\title{
AOR
}

Selected Papers of \#AolR2021:

The 22nd Annual Conference of the

Association of Internet Researchers

Virtual Event / 13-16 Oct 2021

\section{The online life of literacy education: How the 2018 \#PhonicsDebate is reshaping the field}

\author{
Naomi Barnes, Queensland University of Technology \\ Introduction
}

For a full discussion of the findings this paper, since submission to AoIR has been published in the Australian Educational Researcher (see Barnes, 2021). Below is an extended abstract of the paper to accompany the video.

This paper provides an overview of the Reading Wars as a site of discursive struggle. Using a Bourdieu (1993) facilitated digital sociology, this paper presents a case study of the 2018 hashtag \#PhonicsDebate to illustrate how whole language (WL) literacy researchers and cognitive scientists who advocated for universal synthetic phonics (USP) used social media as a space to navigate, negotiate and reimagine the contours of the field of literacy research for the Australian Curriculum. Using a digital sociological account of online events associated with the 2018 Phonics Debate hosted by the Australian Centre for Educational Research and the think tank the Centre for Independent Studies, this paper works to illuminate and challenge contemporary understanding of the politics online. If policy researchers are to clarify the relationship between politics and their field in the 21st century we must understand how boundaries are negotiated using digital tools and how fields are imagined. This digital sociology will aims to help re-evaluate our understanding of how socially mediated environments have transformed how education professional communities work.

In remixing Bourdieu's field of literary production to become a field of online literacy production, two key sociological questions emerge which will be used to interrogate the digital data and associated networks. Firstly, what does it mean for an academic literacy researcher to claim a role at the centre of literacy research and to take on the role of judge as to who gains admission to that field? Likewise, what does it mean for noneducation researchers and literacy advocates to negotiate, navigate and reimagine a literacy research field that includes them?

\section{Methodology}

This paper uses a qualitative critical network (Barnes, 2021) digital sociology that uses small data (Latzko-Toth et al., 2017) to bring together network theory and social media 
methodologies. The social media analyses were conducted using two different data collection approaches. The first involved Twitter, and the other a cross-platform, manual internet archive research.

The small data sets were comprised of media objects using the following parameters:

1. Twitter scraping using \#phonicsdebate, \#phonicscheck, associated key words "teaching + reading", and "phonics". These were collected from the two-week period either side of 31st July 2018 where a live-streamed YouTube debate considered the value of universal synthetic phonics. The tweets were those from identified Australian Twitter accounts, but the dataset did include international participation if an Australian account retweeted a broadcast

2. The YouTube debate and transcript

3. Media articles and blogs that were about the Australian phonics debate, published between June 2018 and December 2019 or hyperlinked in the Twitter dataset. 96 media objects were collected and attributed to a collective. Using CrowdTangle (crowdtangle.com), a tool for collecting interaction metadata on Facebook, Twitter, Instagram and Reddit, I assessed Facebook interaction impressions on the content to get a sense of their impact.

The data were analysed using thematic analysis, matching the tweets to the debate transcript to ascertain which discourses attracted the most attention from the audience and how that attention then played out over the following 18 months through blog posts and news media articles.

\section{Findings}

Cognitive scientists as advocates of universal synthetic phonics (USP) successfully negotiated entry into the field of literacy research by using social media, news media and traditional lobbying to bypass education literacy researcher's dominance over which approaches to reading in the Australian Curriculum. The 2021 review of the Australian Curriculum: English included the USP flagship "decodable texts" in Foundation and Grade 1 descriptors. They also successfully advocated for the overhaul of initial teacher education to include an additional unit dedicated to the teaching of reading (traditionally taught alongside writing). Both these successes for USP advocates were initiatives opposed by many WL literacy researchers. This raised questions about how cognitive scientists were able to renegotiate the field of literacy research in Australian teacher education.

The cognitive scientist dominated USP collective used "highly stylized" (Stern, 2016, p. 3) strategies, such as extensive use of social media and drawing on established relationships with policy makers, to redraw the lines of field. The WL literacy researcher collective accused the other of being aggressive - but in doing so raised questions about what it means to claim the central role in the field and act as judge about what literacy research should inform teacher education and what does not. Social media analysis enabled the identification of two major of discursive struggle that assisted in the renegotiation of the field. By mapping the tweets against the debate, Figure 1 shows that the advocates for USP reacted most strongly to assertions that reading begins at birth and the claims of phonics package commercialisation (see Barnes, 2021 for further analysis of these claims). These issues of contention featured in follow-up blogs and 
news media produced by USP advocates, while WL advocates pushed their collective expertise as a reason to retain authority on the field.

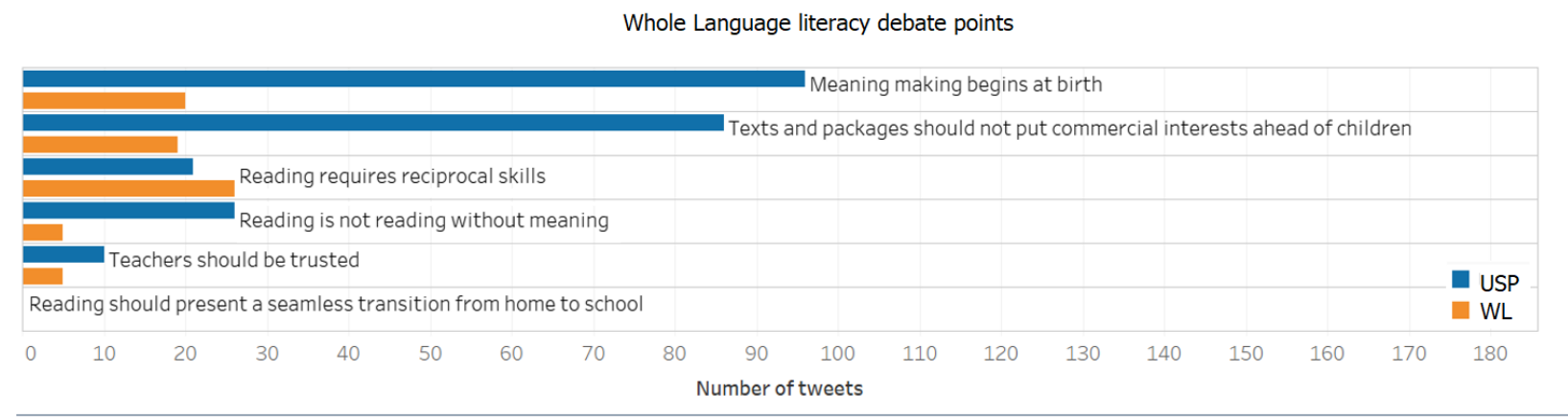

Universal Synthetic Phonics debate points

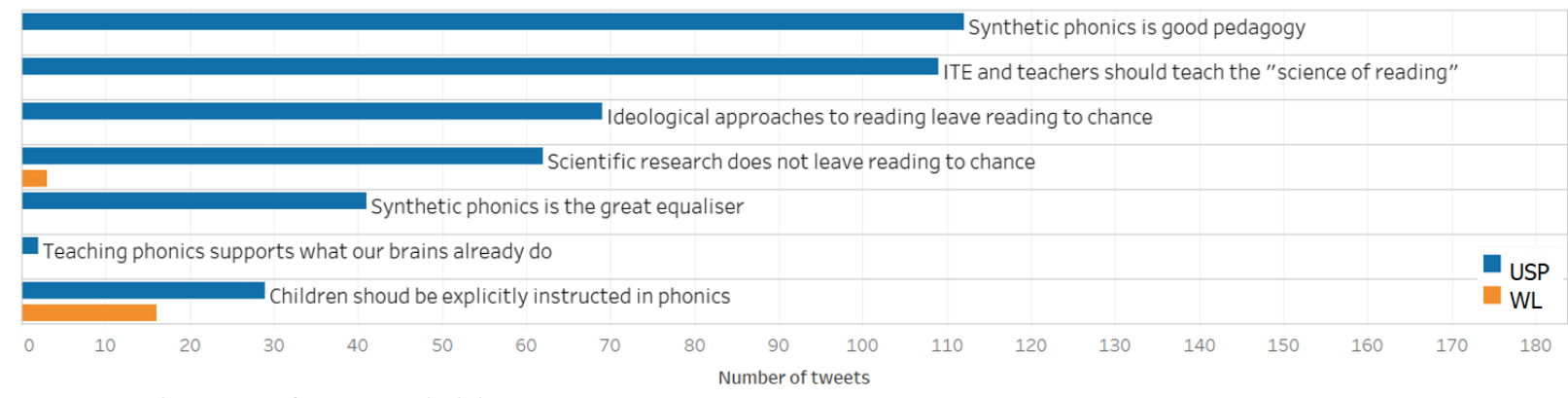

Figure 1. Alignment of tweets with debate points

Figure 2 shows that USP advocates harnessed the collectivising power of social media, legacy news media, and professional (teacher journals) media, effectively blanketing social media content with their perspective. Their content creation was substantially more prolific, had greater variety of texts, and were engaged with on a significantly larger scale than the WL collective over the 18-month period.

Barnes, N. (2021, October). The online life of literacy education: How the 2018 \#PhonicsDebate is reshaping the field. Paper presented at AolR 2021: The 22nd Annual Conference of the Association of Internet Researchers. Virtual Event: AolR. Retrieved from http://spir.aoir.org. 


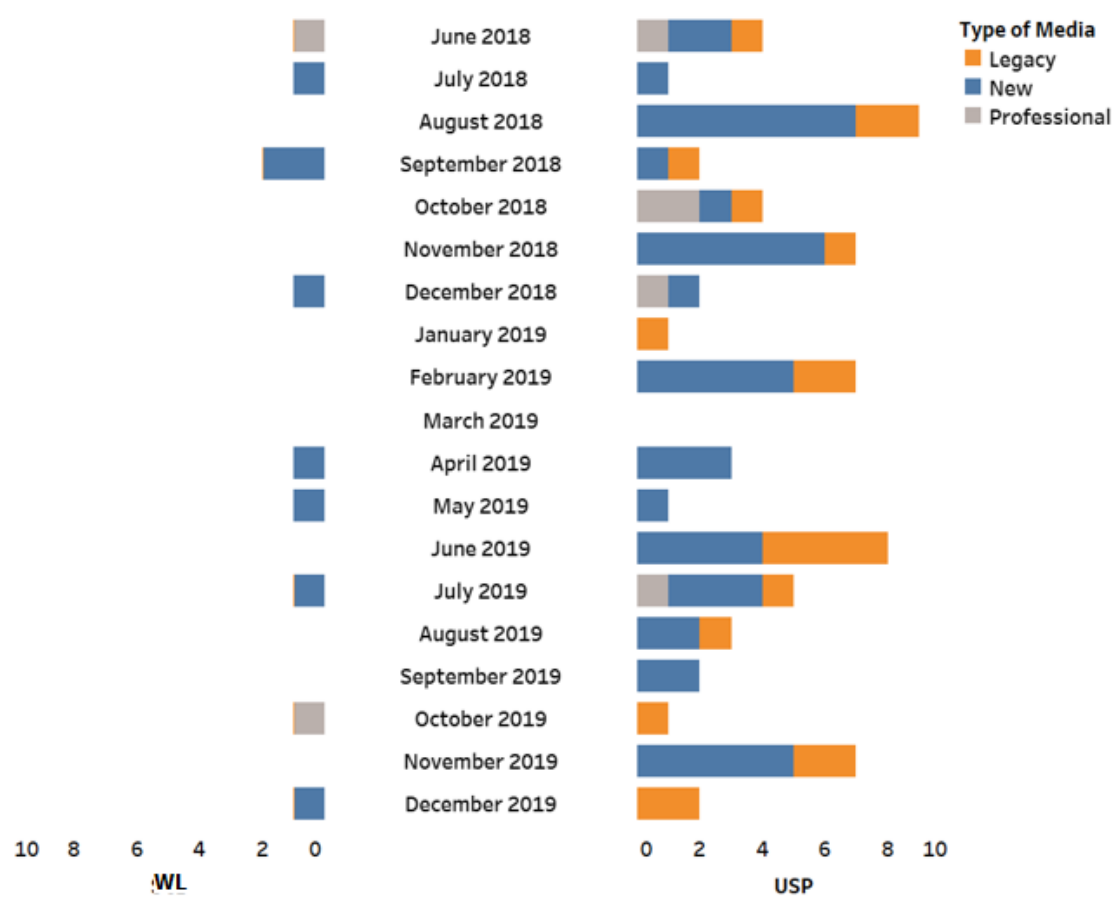

Figure 2: Production of online content about phonics over the 18 month period

The USP's impact on Facebook was also substantially higher than the WL collective (see Figure 3).
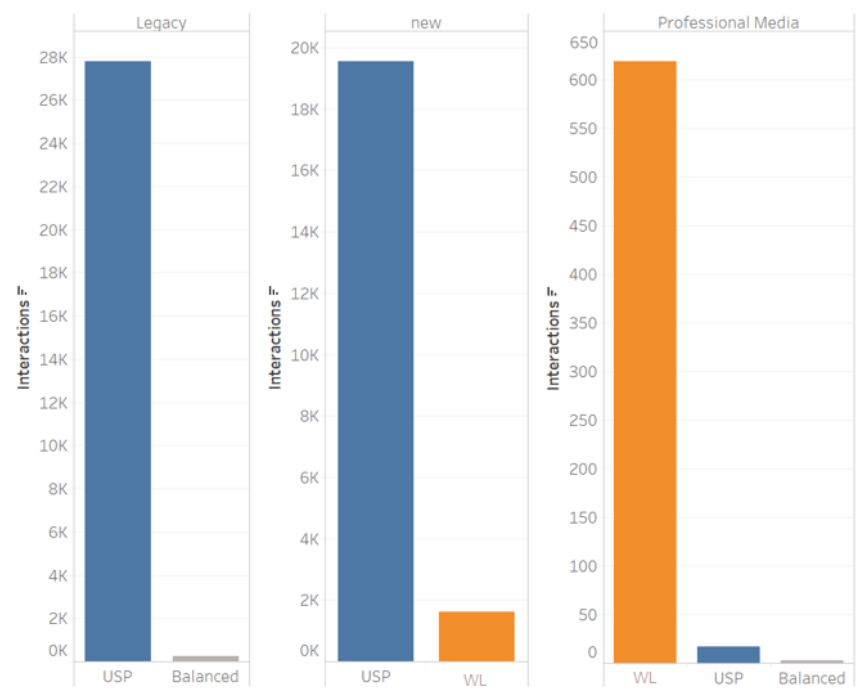

Figure 3: Views of online content about phonics over the 18 month period

The use of social media demonstrated in this paper where policy advocates attempt to redraw the lines of the field of literacy research is a sociological transformation that all policy researchers must be aware of - not just those interested in Internet research. The

Barnes, N. (2021, October). The online life of literacy education: How the 2018 \#PhonicsDebate is reshaping the field. Paper presented at AolR 2021: The 22nd Annual Conference of the Association of Internet Researchers. Virtual Event: AolR. Retrieved from http://spir.aoir.org. 
public shift in authority from expertise and rigorous methodology to personalised experience and virality that social media has brought (Brooks, 2012), is a rhetorical revolution that cannot be dismissed or underestimated.

\section{References}

Barnes, N. (2021). The social life of literacy education: how the 2018\# phonicsdebate is reshaping the field. The Australian Educational Researcher, 1-18

Bourdieu, P. (1993). The Field of Cultural Production: Essays on Art and Literature. Columbia University Press.

Brooks, S. (2012). Speaking Truth to Power: The Paradox of the Intellectual in the Visual Information Age. In S. Brooks, D. Stasiak, \& T. Zyro (Eds.), Policy Expertise in Contemporary Democracies (pp. 69-85). Routledge. https://doi.org/10.4324/9781315601120

Latzko-Toth, G., Bonneau, C., \& Millette, M. (2017). Small data, thick data: Thickening strategies for trace-based social media research. In L. Sloan \& A. Quan-Haase (Eds.), The SAGE Handbook of Social Media Research Methods (pp. 199-214). SAGE.

Stern, K. J. (2016). Reimagined Communities: An Introduction. In The Social Life of Criticism (pp. 1-22). University of Michigan Press; JSTOR. http://www.jstor.org/stable/10.3998/mpub.8833813.3 